\title{
Avaliação da Capacidade de Carga DA ILHA DO MEL, PR: PERSPECTIVA DE PROPRIETÁRIOSDO SETOR DE HOSPEDAGEM
}

\author{
Matias Poli Sperb \\ MestreemAdinistracãopdaUnivesidadeFeekal doParaná, \\ DautarandbemGestãoeDesenvdvinentodeTunismoSustentáved \\ pdaUniversidadedeMálaga- UMA, Espanha. \\ mapdis@gmil.com
}

\section{RESUMO}

O turismo na Ilha do Mel, PR (E stado do Paraná), desenvolveu-se em curto período, causando inúmeros impactos negativos. Em face desses impactos, foi estabelecido em 1995 um número de Capacidade de Carga da Ilha do Mel, PR. Este artigo, baseado em um estudo de caso exploratório-descritivo e mediante a perspectiva de trinta empreendedores do setor de hospedagem da Ilha do Mel, PR, procurou avaliar os resultados de tal controle no local. Entre os resultados verificados, percebe-se que a questão econômicaé a de maior preocupação dos empreendedores, porquanto o número de visitantes não é satisfatório para atender à oferta de todos os empreendimentos pesquisados. D efende-se o controle de demanda; mas importa que ele seja ampliado. Por outro lado, a Ilha do Mel, PR passa por problemas de impacto ambiental, pelo que se alvitra a diminuição de demanda por uma parte; por outra, medidas paralelas para resolver os problemas mais gritantes.

Palavras-chave: Capacidade de Carga. Turismo Sustentável. Setor de Hospedagem.

\section{ABSTRACT}

TaurisminIllhadoMd, PR (Paraná State) deddopedina shart period of time, causing countless negativeimpads Due to these impads in 1995, a "CamyingCapaityNumbe" for theisand was established This artidetries toevaluate theresults of surh restriction It isbased on an exploratoryand desciptivecasestudy and through thepespeetive of thirty businessmen from thelouging setor of Illha dbMd, PR. Amongtheresults found, it is perceived that the eonomicissueis theentrepreneurs' geatest conem, that is why the number of visitants is not enough to meet the sudied businesses supdy. Thedamand contrd is defended, but it isimpartant toinmease it. Ilha db Md, PR goes through enviramental impad problems for this reason, it is suggested a deremsein demand and theadpption of paralle measures to sdvethemost extremeprddens.

Key words: Carryingcapadity. SustainadeTaurism Lodging Setar. 


\section{INTRODUÇÃO}

O setor de turismo já foi considerado na década de 1960 a "indústria sem chaminés" e uma esperança de desenvolvimento econômico para países pobres. Atualmente, está mais do que comprovado que esta também é atividade econômica que degrada o meio ambiente. Ademais, pode ensefar ainda mais exclusão social e pobreza. Segundo Dias (2003), um destino turístico pode ter um boomde procura de um momento para outro, mas também pode entrar em decadência com a mesma velocidade com que cresceu. Nesse aspecto, o turismo, mais que outra atividade, muito depende do planejamento e do contínuo monitoramento do aspecto geográfico onde se desenvolve.

A massificação de um lugar turístico, assim, representa um risco em potencial máximo para a degradação do ambiente natural e a ruína do próprio turismo. Nesse sentido, Krippendorf (1975 apud RODRIG UES, 2000) manifestou-se contrário ao grande afluxo de pessoas aos recursos, alegando que "o turismo destruirá o turismo". Hetzer (1965) argumentou que, depois de terem arruinado o seu próprio ambiente, as pessoas que querem dispor de um ambiente natural se aglomeram em outros locais para destruir o ambiente de outros, em suas frenéticas tentativas de escapar, nem que seja por um curto tempo, da pressão competitiva, poluição, crime e trabalho alienante ("corrida dos ratos"). D ias (2003) enfatiza que $0 \mathrm{im}$ pacto do turismo sobre o meio-ambiente é inevitável. 0 que se pretende é mantê-lo dentro de limites aceitáveis, para que não provoque modificações ambientais irreversíveis e não prejudique o prazer do visitante ao usufruir o lugar. Para Wahab e Pigram (1997), nem todas as mudanças geradas pelas atividades de turismo levam, necessariamente, à degradação. Pelo contrário, se forem levadas a cabo de forma responsável, o desenvolvimento do turismo pode contribuir substancialmente para melhorar 0 ambiente e levar a um aumento de prazer do turista e assegurar proteção ecológica.

Com base neste contexto, esta pesquisa volta-se para a análise da Capacidade de Carga da Ilha do Mel, localizada no Litoral do Paraná. Este tipo de medida, ou estratégia gerencial, propõe-se controlar a demanda de um local turístico, visando a assegurar a sua sustentabilidade. Para verificar os efeitos desta estratégia, que foi estabelecida há mais de dez anos na Ilha do $\mathrm{Mel}, \mathrm{PR}$, foram entrevistados trinta proprietários do setor de hospedagem do local, além de um gestor público, tendo sido feita, ainda, a análise documental. Mais especificamente, buscou-se verificar, na perspectiva desses empreendedores, quais são os resultados que esta medida vem produzindo no local, suas deficiências e o que ainda não foi solucionado por este controle de demanda. Cumpre seja dada maior atenção à continuidade turística nestailha.

\section{DESEN VOLVIMENTO DO TURISMO NA ILHA DO MEL, PR}

O desenvolvimento do turismo que se tem documentado na Ilha do Mel, PR, data do início do século XX. Na primeira fase do turismo local, a Ilha era muito procurada por famílias da classe alta de Curitiba que iam lá veranear; pode ser considerado o primeiro recanto turístico do litoral do Paraná (ITCF, 1986).
D urante a Segunda Guerra Mundial, a Ilha foi considerada "zona de guerra", aliada à construção da Estrada das Praias, em 1926; foi bloqueado momentaneamente o desenvolvimento da atividade turística (SEMA, 1996).

Segundo Kim (2004), até a década de 1970, a população local vivia basicamente da pesca artesanal e da agricultura para consumo próprio; contudo, a abertura da estrada de acesso às praias permitiu o desenvolvimento turístico e o estabelecimento dos balneários, primeiramente os do sul, como Matinhos e Guaratuba, e posteriormente aqueles ao norte, até Pontal do Sul, por onde é feita a travessia para a Ilha. Na concepção de A thayde e Tomaz (1995), o início da década de 1980 foi marcado por uma mudança, quando o fluxo de turistas aumentou consideravelmente e a população passou a conviver mais de perto com a dinâmica social trazida por eles. Em decorrência, ocorreram alterações nas práticas sociais, mudando radicalmente 0 estilo de vida dos nativos. No final da década de 1980, 0 desenvolvimento do turismo também foi favorecido pelo estabelecimento da energia elétrica, com a Usinaa Diesel daCOPEL, localizada na extremidade sul da Ilha.

Conforme Kim (2004), durante as décadas de 1980 e 1990, a Ilha também recebeu muitos imigrantes: pessoas da classe média alta buscaram qualidade de vida, instalando comércios, e pessoas com menor poder aquisitivo atrás das oportunidades de emprego, geradas por esses estabelecimentos. Na década de 1990, paralelamente ao crescimento de visitantes, na concepção de Esteves (2004, p. 209), o perfil dos turistas que frequentavam a Ilha do Mel, PR foi se alterando para um tipo de "homourbano desenvolvimentista". Este fato decorre da crescente busca, por parte de pessoas da cidade, por lugares com ambientes naturais em bom estado de conservação. Também contribui 0 papel da mídia na divulgação da Ilha, a criação de infraestrutura, destacando-se: a construção de ancoradouro em Nova Brasília; construção de uma praça de animação para a comunidade e visitantes; edificação do Escritório local do IAP (Instituto Ambiental do Paraná)/ Centro de Recepção de Visitantes; Edificação do Posto da Polícia Florestal; reorganização das trilhas, e daquela voltada ao turismo: construção de pousadas; restaurantes; 0 funcionamento de linhas regulares de barco, entre outros.

Nessas condições, segundo Neto (1999), no início do desenvolvimento mais proeminente do turismo na Ilha do Mel, PR, no primeiro momento, na década de 1980, sobressaíam as casas de veraneio e, a partir de 1995, começou a predominar a instalação de estabelecimentos comerciais voltados ao turismo. 0 número de segundas-residências aumentou mais de $50 \%$, entre 1980 e 1997, ao passo que as residências de moradores permanentes, predominantemente de nativos, aumentaram apenas 27\%. De 1997 a 2004, entretanto, houve redução no número de casas de veranistas em $50 \%$ das residências. Segundo Esteves (2004, p. 94), "a queda do número de residências de veraneio não significa decréscimo de ocupação de imóveis destinados ao turismo, visto que muitas destas casas foram transformadas em estabelecimentos de uso predominantemente comercial ou misto".

Portanto, até 2004, segundo pesquisa de Esteves (2004), havia 107 pousadas e 58 restaurantes; foi verificado um de- 
créscimo no número de casas de veraneio, com relação a 1997. Assim, no que diz respeito ao número de pousadas, houve aumento de mais de $280 \%$ de 1993 até 2004, enquanto o número de restaurantes aumentou um pouco mais de $200 \%$ neste mesmo período.

Consoante Neto (1999, p. 157), a maioria dos proprietários é formada por investidores que migraram para a Ilha, a fim de lucrar com atividades econômicas ligadas ao turismo. Constituindo estes proprietários como de "de fora", aí distinguiram-se o migrante investidor em si e o turista proprietário de "segunda residência", que acabou por transformá-la em comércio. Segundo Esteves (2004, p. 95), "o número elevado de empreendimentos de proprietários de fora é facilmente explicável em virtude da superioridade econômica deste tipo de investidor sobre o nativo e também devido a pequena cultura empreendedora dos ilhéus".

Com relação ao número de turistas da Ilha, por meio de dados fornecidos pela Ecoparaná (2005)1 , desde o início de janeiro de 2000 até dezembro de 2004, verifica-se que a procura por este destino turístico vem diminuindo consideravelmente. Q uestionam-se quais seriam os motivos principais desta redução; especula-se que os problemas ambientais da Ilha do Mel, $\mathrm{PR}$, em decorrência da própria atividade de turismo, são fortes inibidores de visitantes em busca de lazer junto a áreas de preservação ambiental.

No gráfico a seguir, verifica-se que houve redução gradual de mais de 30\% na visitação total de turistas a Ilha do Mel, PR, desde janeiro de 2000 a dezembro de 2004.

\subsection{A Sustentabilidade do T urismo L ocal}

Variados foram os estudos sobre as modificações nos aspectos relacionados ao meio ambiente e à socioeconomia na Ilha do Mel, PR, em razão das mudanças ocorridas abruptamente nos últimos 30 anos, sobretudo em face da procura turística aumentada pelo local. Para E steves (2004), o turismo modificou radicalmente a paisagem e a sociedade da Ilha do Mel, PR, tornando-se a sua principal atividade econômica. De pacatalocalidade de pescadores no final da década de 1970, hoje se constitui em destacado ponto turístico do Paraná e do Brasil.

Em razão daprocura elevada de turistas pela Ilha que veio aumentando a partir da década de 1970, segundo Elias, Martinez e Esteves (2003), nas áreas da Ilha do Mel, PR, onde são permitidas a concessão de lotes e a construção de edificações, o ritmo de ocupação foi intenso e totalmente desordenado. Na concepção de Esteves (2004), os caiçaras eram seduzidos a vender áreas de alto valor a preços relativamente baixos, perdendo seu espaço territorial para empreendimentos imobiliários e turísticos. Além disso, muitas das obras destinadas ao turismo são de alvenaria e possuem mais de um pavimento, o que é proibido pelas normas vigentes relativas a edificações na Ilha do Mel, PR.

Para Silveira (1998, p. 228), o crescimento turístico dalocalidade também foi totalmente desordenado, como ele exprime, em razão da ausência de atuação efetiva do governo: "por muito tempo houve ausência de uma política de planejamento e gestão que fosse eficaz para lidar com a maneira caótica como 0 turismo vinha desenvolvendo-se na área".

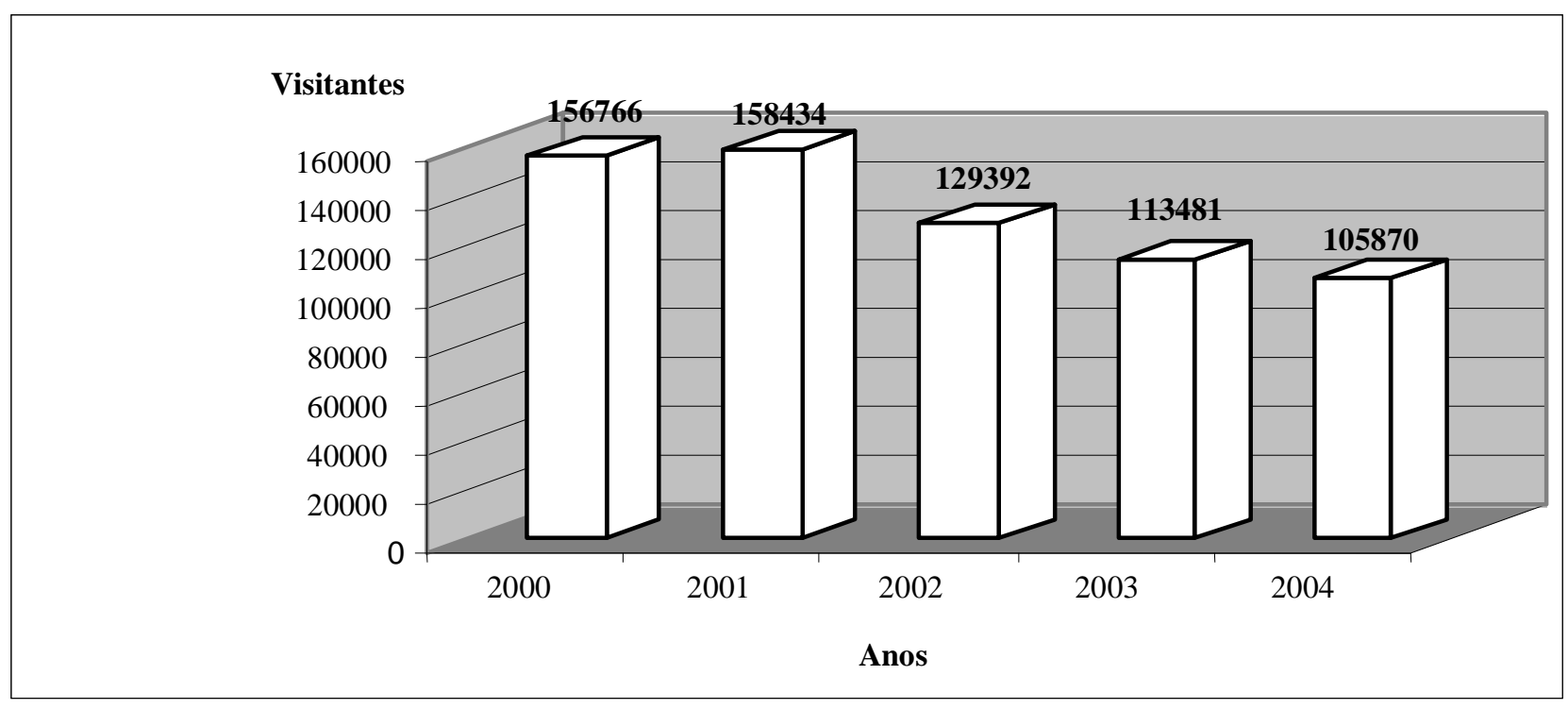

Grafico 1: Total de Visitantes a Ilha do Mel, PR - 2000 a 2004

Fonte: Ecoparaná (2005).

Na concepção de Elias, Martinez e Esteves (2003), paralelamente ao desenvolvimento tuństico e ocupação originária desta atividade, ocorreram desagregação cultural e social da comunidade local e a degradação da qualidade ambiental, aspectos que serão mais bem apreciados no próximo subitem.
Entre os problemas socioambientais provocados pelo turismo desordenado, segundo Esteves (2004), destacam-se: "a violência e o consumo de drogas, o emprego da mão de obra dos nativos em atividades consideradas menos nobres como 0 transporte de cargas, serviços gerais de limpeza e cozinha, coleta 
de lixo etc., precariedade nas questões relativas à saúde e à educação, descaracterização da paisagem natural, grande quantidade de lixo jogado e acumulado, destruição da flora e da fauna e degradação da qualidade daágua".

Em perspectiva sociocultural, para Kraemer (1996), o crescimento da atividade turística na Ilha do $\mathrm{Mel}, \mathrm{PR}$, a partir da década de 1980, aliada àimplementação do sistema de transporte e à instalação daluz elétrica em 1988, foram os principais fatores que contribuíram para a descaracterização cultural da população Ilhéu. Assim, hábitos antigos, como a dança do fandango, praticada em várias localidades do litoral paranaense, e mesmo os bailões (forrós), foram abandonados pela população, que passou a vivenciar novos hábitos trazidos pelos turistas.

Kim (2004, p. 127) desenvolveu pesquisa sobre o estado atual dos três aspectos de sustentabilidade (econômico, social e ambiental) da Ilha do Mel, PR. Verificou que 0 aspecto econômico é aquele que se mostra mais "sustentável", mas, apesar da geração de renda, "há influências negativas no aspecto social". 0 aspecto social "é aquele que recebe mais influência negativa dos indicadores ecológicos e econômicos, e aquele que tem as piores respostas dos indicadores, ou seja, se trata do aspecto menos sustentável".

Para essa autora, comparando a realidade aos objetivos das propostas e planos que guiaram a aplicação das políticas voltadas para a Ilha do Mel, PR ao longo do tempo, "vemos que sempre houve uma oscilação entre dois extremos: de um lado, a disposição em preservar a natureza e, do outro, a vontade de favorecer o desenvolvimento do turismo de massa falsamente anunciado como ecoturismo" (KIM, 2004).

\section{CONCEITO DE CAPACIDADE DE CARGA}

0 advento do conceito de capacidade de carga na esfera do turismo, segundo Pires(2005), não por coincidência, corresponde ao mesmo período em que despontaram de modo mais contundente, em várias partes do mundo, os efeitos negativos dos impactos decorrentes desse mesmo turismo. Nesse período, correspondente à década de 1970, surgiram os primeiros estudos com o objetivo de produzir conhecimento, ocasionar metodologias e oferecer respostas tecnicamente respaldadas à inquietação então reinante: quantas pessoas determinado local ou ambiente pode suportar antes que se deteriore ou se descaractenize de formairreversível?

Historicamente, é provável que os cálculos mais recentes de capacidade de carga estão relacionados com a gestão do gado, ou seja, o número de animais que uma pastagem pode sustentar. A capacidade de carga animal está associada a três categorias: mínima, máxima e ótima (SHELBY e HEBERLEIN 1986, p.8). A capacidade mínima estabelece o número de animais que ecossistemas podem sustentar em tempos de alta pressão, como em épocas de estiagem. 0 nível máximo indica o número máximo de animais que determinado ambiente pode suportar, sem prejuízo para esse meio ambiente. Jáa capacidade de carga ótima é um intermediário que indica a dimensão de qualidade, ou seja, o melhor retorno para a produção das culturas sem comprometer o meio ambiente.
No turismo, a capacidade de carga é posta em prática mediante estratégias gerenciais da demanda turística e recreativa no meio ambiente natural, sobre a qual recai grande parte das atenções e dos esforços de planejamento e gestão da demanda turística e recreativa no mundo todo. Inicialmente, segundo Pires (2005), adotou-se a expressão em inglês CarryingCapaaty, com a sua tradução operacional para a língua vernácula, "capacidade de carga", ou a versão similar, "capacidade de suporte". Assim, tomados essencialmente no sentido operacional do âmbito do turismo, tais termos adquirirem significado equivalente; poderia ser descrito basicamente "o que um determinado ambiente possui para suportar o afluxo de visitantes e turistas sem perder as características de sua originalidade ou ter ameaçada a sua integridade". Infere-se, portanto, a ideia da inevitabilidade do impacto humano sobre o meio, bem como a aceitação de que esse meio poderá absorver ou tolerar impactos que resultem em alterações aceitáveis, ou seja, não comprometedoras de referida originalidade ou integridade. Neste sentido, segundo Mieczkowsld (1995), a capacidade de carga no turismo deve seguir os seguintes princípios fundamentais:

- não deve ser inferior à qualidade do ambiente natural. Em outras palavras, o recurso não deve causar um grau inaceitável de deterioração (entendida como uma situação em que o ambiente permanece sustentável);

- não deve diminuir a qualidade percebida da experiência de recreação ea satisfação dos participantes; e

- não deve prejudicar o bem-estar dos residentes, ou seja, que os impactos do turismo no destino não excedam 0 nível máximo de tolerância de residentes locais.

No contexto do paradigma do desenvolvimento sustentável, constata-se ampliação das preocupações que envolvem a concepção de Capacidade de Carga, agora incluindo também a questão sociocultural e econômica relativa às populações residentes nas destinações turísticas. Segundo Dias (2003, p. 81), 0 informe da Comissão sobre o Desenvolvimento Sustentável, de 1999, no capítulo II, item 27, também faz importante ponderação sobre capacidade de carga nesta direção, pois o documento aponta que não se devem impor limites em âmbito mundial e que as decisões devem basear-se em processos locais de que participem diversas entidades, pois cada lugar terá necessidades e problemas diferentes.

Para Ruschmann (2001), a capacidade de carga dependerá do comportamento dos indivíduos, da dificuldade de determinação da quantidade ideal de turistas e na sua distribuição no tempo e no espaço, dos meios disponíveis para conter os excessos e na escolha de modelos de desenvolvimento que se tenciona implantar. As complicações surgem quando se considera 0 nível ou limite de uso apropriado a um recurso específico. De acordo com a natureza do recurso como entidade subjetiva e perceptiva, diferentes tipos de usuários terão diferentes necessidades e expectativas em relação a ele. Consequentemente, a tolerância desses grupos de usuários (por exemplo: usuários de jeski e canoístas) varia.

Mesmo nos países dotados de condições estruturais e financeiras favoráveis, a plena gestão do controle dos impactos 
e dos demais objetivos de manejo das áreas naturais protegidas, a adoção dosatuais modelos (LAC, VIM, VAMP, TO M eVERP), com todos os seus desdobramentos metodológicos e em toda a sua abrangência, tem-se mostrado desafio permanente aos seus protagonistas, exatamente no aspecto da gestão dos distintos interesses e influências que intervêm no desenrolar desse processo (PIRE S, 2005). Assim, segundo o referido autor,

Essa rotina, infelizmente, ainda não se aplica no Brasil, onde sequer foram superadas as limitações e circunstâncias adversas (escassez e despreparo de pessoal, falta de verbas, desestruturação institucional etc.) para 0 estabelecimento de condições básicas de manejo das áreas naturais, como, por exemplo, a regularização fundiária, a delimitação territorial, a implantação da infra-estrutura e a fixação de pessoal. (p. 8).

Alguns outros autores realizaram uma série de críticas à capacidade de carga turística. Por exemplo, Lindberg e McCool (1998) argumentam que a capacidade de carga pode ser um conceito controverso, problemático em sua implementação, e sua utilização élimitada ao desenvolvimento de orientações para as políticas públicas. Brown etal. (1997) reconhecem que o estabelecimento de um padrão de nível mínimo da atividade turística é difícil, por diversas razões. Primeiro, em termos de ciência e compreensão dos sistemas ecológicos e processos, faltam dados precisos. Em segundo lugar, em termos do processo político de tomada de decisão e planejamento em que se estabelecem essas regras, a aplicação desses regulamentos é fraca. Enfim, em virtude da complexidade do tema, alguns autores (CANE STRELLI e COSTA, 1991; SALEEM, 1994) se criticam em torno da questão, por se darem conta de que seus modelos deveriam incluir mais dados e de que mais investigação empírica deveria ser feita, em diversas áreas de estudo relacionadas com o território, para possibilitar uma definição mais exata destes índices do turismo.

\section{METODOLOGIA}

Considerando os objetivos deste estudo, elaboram-se as seguintes perguntas de pesquisa: 1) Como foi estabelecida a Capacidade de Carga da Ilha do Mel, PR? 2) Como está sendo avaliado o controle da Capacidade de Carga na Ilha do Mel, PR, por proprietários do Setor de Hospedagem da localidade? Em função de seus objetivos, a pesquisa pode ser classificada como exploratória e descritiva. A pesquisa apresenta caráter exploratónio, pois aborda tema com pouco conhecimento acumulado e sistematizado. Pode-se considerá-la também como descritiva, porquanto se busca conhecer um fato ou fenômeno sem precisar recorrer a relações causais entre suas variáveis. A pesquisa procura descrever um fato ou fenômeno desde a primeira aproximação, ou seja, a partir da pesquisa exploratória.

0 método escolhido para esta pesquisa é o método de estudo de caso, sendo tomado o Setor de Hospedagem da Ilha do Mel, PR. Segundo Y in (2005), o estudo de caso é preferido quando o tipo da questão a ser pesquisada é de forma "como" e "por quê". Também é preferido quando o controle que 0 investigador tem sobre os eventos é muito reduzido, ou ainda quando o foco temporal está em fenômenos contemporâneos, dentro do contexto de vida real. Para G odoy (1995), o estudo de caso tem por objetivo proporcionar vivência da realidade por meio da discussão, análise e tentativa de solução de um problema extraído da vida real. Godoy (1995, p. 25-26) expõe ainda que, "adotando um enfoque exploratório e descritivo, o pesquisador que pretende desenvolver um estudo de caso deverá estar aberto às suas descobertas". Ainda é importante ressaltar, mesmo que os estudos de caso sejam a essência da pesquisa qualitativa, podem comportar dados quantitativos para aclarar algum aspecto da questão investigada. Quando isso acontece, podem, geralmente o tratamento estatístico não é sofisticado.

Com relação à coleta de dados, segundo Y in (2005, p.112), "nenhuma fonte de evidências possui vantagem indiscutível sobre as outras. Na verdade, as várias fontes são altamente complementares; o bom estudo de caso utilizará o maior número possível delas" . E sta pesquisa foi realizada mediante a utilização do método documental, no que diz respeito aos dados secundários e, para a coleta de dados primários, foi adotada a técnica de entrevista pessoal com a utilização de questionário composto, principalmente, de perguntas abertas. Foram entrevistados trinta proprietários de pousadas, o que corresponde a cerca de 30\% do universo destes empreendimentos, de acordo com levantamento de campo em toda a ilha feito por Esteves (2004). Também foi entrevistado um gestor do setor público responsável pela coordenação do IAP na Ilha do Mel, PR.

\section{A CAPACIDADE DE CARGA NA ILHA DO MEL, PR}

A capacidade de carga, ou de suporte da Ilha do Mel, PR, foi estabelecida em 1996, com base no "Plano de G estão da Ilha do Mel, PR". A justificativa para o seu estabelecimento foi identificada neste documento em virtude da ação antrópica ao meio ambiente que "sempre 0 altera, e raramente de modo favorável, a médio elongo prazo". (IAP, 1996, p. 65).

$\mathrm{O}$ documento faz algumas considerações amplas para 0 estabelecimento de capacidade de carga, como a necessidade de se conhecer fatores: físicos (clima, solo, geologia, hidrologia...); biológicos (fauna, flora, ecossistemas...); materiais (infraestrutura, transporte, comunicações...); sociais e econômicos (demografia, atividades econômicas, sensibilidade social...). Ademais, este documento salienta que a capacidade de carga de um ambiente pode ser flexibilizada em função do grau de civilidade dos moradores e visitantes; assim, a "informação e a educação ambiental são fatores importantes a considerar".

Para o estabelecimento efetivo da capacidade de carga da Ilha do Mel, PR, entretanto, foram levados em conta apenas quatro variáveis, segundo IAP (1996, p. 67): oferta de água potável; emissão de efluentes elixo; disponibilidades de energia elétrica e a capacidade de alojamento.

Com relação à oferta de água potável, pelos dados disponíveis pela SANEPAR (Companhia de Saneamento do Paraná) (1991 apud IAP, 1996), a rede de fornecimento pública de água na Ilha poderia atender 636 moradores e 2011 visitantes. Os poços particulares (que naquela época e ainda hoje são muitos) não foram contabilizados; contudo, mesmo que não tenha sido considerado o número destes poços, a disponibilidade de água potável foi elevada a um fator importante para 0 estabelecimento da capacidade de carga. 
Com relação a efluentes, naquela época não havia um cálculo de volume produzido, entretanto, por meio de análises desenvolvidas pela SURHE MA (Secretaria de Estado do Desenvolvimento Urbano e Meio Ambiente) (1994 apud IAP, 1996), já se sabia que eram comuns as contaminações por coliformes fecais na água da rede.

Quanto ao lixo, verificou-se que este fator era de "mais fácil solução", sendo de "fácil remoção" e "tratamento", necessitando apenas de "decisão administrativa" de como executar este processo. 0 problema maior, verificado com relação ao lixo, referiu-se ao lixo orgânico e "de banheiro", os quais são "enterrados ou jogados ao acaso na Ilha..." (IAP, 1996, p. 68).

Com relação à capacidade de fornecimento de energia elétrica, quando naquela época ainda era utilizado o gerador a diesel, este recurso foi verificado como forte limitador determinante para a capacidade de carga: "O s picos de consumo observados nos feriados de setembro de 1995, quando havia cerca de 5.600 pessoas na Ilha, indicam riscos ao sistema de geração e possibilidade de racionamento". (IAP, 1996, p. 68).

No que tange à capacidade de alojamento daépoca, verificou-se que, com base em dados da Polícia Militar e do IAP (1995 apud IAP, 1996), estes indicavam uma capacidade total de hospedagem de 3.250 pessoas: pousadas e hotel, 1.250 pessoas; campings 2.000 pessoas. Ainda foram somadas as habitações de veranistas, que comportavam mais 1.600 pessoas, chegando a uma capacidade total de alojamento de 4.850 pessoas que, acrescidas de moradores permanentes, perfaziam cerca de 5.500 pessoas.

Relacionando às variáveis anteriores, a capacidade de carga foi estabelecida por este documento da seguinte forma:

\begin{abstract}
A análise conjunta das variáveis, respeitadas as limitações quanto às informações disponíveis, indica que a capacidade de suporte, nas condições atuais, está em torno de 4000 visitantes, incluídos os veranistas com residência na Ilha, não estando incluídos os moradores permanentes. (IAP, 1996, p. 68).
\end{abstract}

Em decorrência desse plano, foi editadaa Resolução 036/ 95, que visa a "disciplinar o número de turistas e visitantes ao perímetro dos terrenos da Ilha do Mel, PR, fixando em 5.000 o limite máximo de pessoas por dia" (PARANÁ, 1995). Portanto, cabe salientar que o número de capacidade de carga estabelecido por lei foi além do que havia sido "constatado" no Plano de G estão da Ilha do Mel, PR de 1996. Além disso, segundo a Coordenação do IAP para a Ilha do Mel, PR (2005), atualmente, o número total de pessoas que vai à Ilha, para ficar pelo menos um dia, está estimado em torno de 1.500 residentes da Ilha, 2.000 veranistas, 5.000 visitantes do limite de capacidade de carga e mais até 1.500 pessoas que podem chegar por vias clandestinas, ou seja, aquelas pessoas que chegam em barcos particulares. Assim, em feriados de alta temporada, o número total efetivo de pessoas na Ilha do Mel, PR pode chegar até 10.000 pessoas num só dia, ou seja, atualmente a Ilha vem recebendo quase $80 \%$ a mais de pessoas do que havia sido calculado pelo IAP em 1996, para períodos de grande procura, e em torno de $100 \%$ a mais do que o permitido pela legislação.
No que diz respeito à capacidade de hospedagem, para esta não foi estabelecido um limite por parte do IAP e, portanto, também aumenta desde 1995 até a atualidade. Segundo a Coordenação do IAP para a Ilha do Mel, PR (2005), em censo feito pelo próprio IAP em janeiro de 2003, foram verificados 7.560 leitos totais, o que representa aumento de mais de 35\% na capacidade hospedagem, se comparados ao número total de leitos de 5.500 verificados em 1995, em dados da Polícia Militar e IAP constantes no Plano de G estão da Ilha do Mel, PR de 1996. Segundo Esteves (2004), só o número de pousadas na Ilha do Mel, PR aumentou em 280\% de 1993 até 2002, sendo verificados 107 destes empreendimentos em 2004.

Por outro lado, segundo dados da E coparaná (2005), em meses com maior densidade de turistas na Ilha, como janeiro, a média diária verificada deste mês, entre os anos de 2000 a 2005, foi de 1.180 visitantes. Isso vem confirmar que a lotação da Ilha acontece apenas nos feriados mais famosos e na alta temporada. Na baixa temporada, a média de visitação diária, nos meses de maio a agosto, ficam em menos de 100 pessoas.

\subsection{Avaliação dos Proprietários de Pousadas}

Como verificado anteriormente, a Ilha do Mel, PR pode receber, ao mesmo tempo, de acordo com a Resolução 036/ 95 do IAP, 5000 visitantes. Procurou-se saber como esses empresários avaliam essa limitação do número de turistas.

Foi verificado que a maioria dos proprietários (83\%) apoia o controle do número de turistas, mas, dentre estes, a maioria também discorda quanto à determinação do número de visitantes ou quanto à forma de controle. Para 13\% dos proprietários, não deve haver esse controle e um número reduzido defendeu, ainda, a ideia de que não seria o número de turistas 0 problema central do impacto ambiental, econômico ou social a Ilha, mas o tipo ou o comportamento de muitos dos turistas.

D entre os respondentes que defenderam o controle do número de turistas, mas que discordam quanto ao número estabelecido pelo IAP, alguns acreditam que 0 limite de 5.000 pessoas é muito alto. Por outro lado, há uma parcela maior de entrevistados a acreditar que 0 limite atual de 5.000 é um número insuficiente de visitantes para a ocupação dos meios de hospedagem.

D entre os proprietários que acreditam que o número atual de visitantes estabelecido pelo IAP está bom ou é elevado, ouviu-se a seguinte argumentação:

Sim, tem que ter este controle porque não existe nenhuma política interna de gestão ambiental. Tem que controlar ao máximo. À medida que as coisas vão melhorando, aí dá para colocar mais gente. D aria para encher as pousadas, desde que houvesse cuidado com esgoto, desde que se preocupassem melhor com o lixo, essas coisas. (INFO RMAÇÂO VERBAL).

Por outro lado, em maior número, alguns proprietários acreditam que o número de turistas deveria ser aumentado pela justificativa principal de que a oferta de estabelecimentos comerciais é maior do que a demanda controlada de 5000 pessoas. D entre estes, verificou-se o argumento de que os turistas não estariam bem distribuídos pelas pousadas da Ilha do Mel, PR, visto que a maioria acaba ficando em pousadas perto dos 
atracadouros. Um aumento no número de turistas, segundo eles, iria possibilitar também a ocupação de pontos mais afastados dos trapiches. Estas opiniões foram mais perceptíveis em Nova Brasília e no lado norte da praia de Encantadas, que são locais mais isolados, distantes dos atracadouros.

0 terceiro grupo, intermediário, refere-se àqueles proprietários que acreditam que o número de turistas deve ser estabelecido principalmente em função da infraestrutura pública da Ilha do Mel, PR, principalmente da capacidade de fornecimento de água, esgotamento sanitário e luz. Também foi mencionado que se houvesse melhor infraestrutura, principalmente com referência a um sistema público de esgotamento sanitário, haveria possibilidade de se aumentar o número de visitantes da Ilha e até a construção de mais estabelecimentos comerciais.

A minoria defendeu a ideia de que a determinação do número de turistas deveria estar em equilíbrio com a infraestrutura, com a educação ambiental e ainda com a capacidade de suporte do meio ambiente da Ilha, como um dos proprietários mencionou:

Então você tem uma infra-estrutura para um uso: os campings, por exemplo. As pessoas acham que há espaço, que cabe mais gente. Mas acontece que tem 0 banheiro limitado. Então não dá para colocar mais pessoas. E as pessoas, mesmo assim, insistem. Não tem controle, fica lixo em qualquer lugar, não tem lugar no banheiro. Então fica tudo uma porcaria. Tem de haver este controle em função da infra-estrutura construída por um lado e depois porque isso aqui é uma reserva, e se você bota muita gente, teria de ter mais educação ambiental e outros cuidados. (INFORMAÇÃO VERBAL).

Com relação ao impacto social dos turistas à comunidade local, uma pequena parcela defendeu um controle no número de visitantes para garantir tranquilidade social à comunidade, como expressou um destes empreendedores:

Sim, tem de haver este controle. Porque quando entra muita gente vira uma bagunça muito grande, um desrespeito, e vira uma baderna; é horrível, sabe? A gente passou épocas aqui em que ninguém dormia, dia e noite. Muito barulho. Esse controle é muito bom. Esse ano que passou foi legal, porque eles controlaram bem. (INFO RMAÇÃO VERBAL).

Treze por cento de proprietários que acreditam que não precisa haver controle nenhum de turistas na Ilha do Mel, PR, justificaram sua opinião pelo fato de que o controle ocorre de forma "natural", de acordo com a procura do número de visitantes e a oferta de meios de hospedagem; ou ainda que a Ilha simplesmente não necessita de controle de visitantes pelo Poder público, por ser o controle uma ação mais prejudicial do que benéfica para a Ilha do Mel, PR, como foi explicado.

[...] eles falam que se não tiver controle vai prejudicar 0 meio-ambiente. Eu acho que não prejudica. Traz mais benefício aqui para a ilha. Se não for o turismo a gente vai viver do quê? Não dá, porque eles fecham lá (a entrada de turistas) e aí não tem para todo mundo. Não precisa controlar o número de turistas. Eu fico me perguntando: antigamente não existia esse controle; nem por isso era destruída a ilha. Não existia o IAP aqui. Por que agora é controlada? (INFO RMAÇÃO VERBAL).

Nesse grupo, também houve queixa sobre o sistema de controle feito pelo IAP, que "conta equivocadamente" os visitantes que vão passar apenas um dia na Ilha. Sendo assim, o número de 5000 pessoas estabelecido para permanecer no local seria menor ainda, em termos de permanência e de utilização dos meios de hospedagem, visto que muitos dos turistas vão à Ilha apenas para passar o dia. Ademais, foi comentado que 0 IAP não estaria controlando os visitantes que regressam, para que haja a permissão de entrada de novos turistas na Ilha. Segundo esses proprietários, esta "negligência" está causando redução ainda maior da ocupação dos meios de hospedagem.

Os empreendedores também foram perguntados se eles pensam que deveria haver controle no número de pousadas e ou de leitos das pousadas na Ilha do Mel, PR, já que existe 0 controle do número de turistas. A maioria dos proprietários (87\%) acredita que sim, que deveria haver algum controle nesse sentido, apesar de os motivos serem muito variados. O utros $10 \%$ dos proprietários acreditam que não, que não deve haver controle estabelecido pelo setor público do número de pousadas e ou leitos na Ilha do Mel, PR. Apenas 3\% dos proprietários não responderam, por não haver uma opinião formada sobre 0 assunto.

Dentre os proprietários que acreditam que deve havercontrole do número de pousadas, e/ ou de leitos em cada pousada, grande parte defende aideia de que esse controle deveria ser baseado na capacidade das pousadas, principalmente no que diz respeito à capacidade de absorção das águas residuárias de emissões. Um dos proprietários expõe sua opinião da seguinte forma:

\begin{abstract}
Precisa haver controle de pousadas e de leitos por pousada também, sem dúvida. Se a pessoa tem uma fossa séptica apta para receber cem turistas, tudo bem. Ago$\mathrm{ra}$, se ele tem uma fossinha pequena e mal cuidada, ele não pode receber. Tem gente que tem uma fossinha de " $2 \times 2$ ", tem gente que não tem uma caixa de gordura, tem gente que acha que uma caixa de gordura é uma caixa de passagem. Tem gente que tem uma caixa de gordura e limpa a cada seis meses apenas. Aí não dá! (INFO RMAÇÃO VERBAL).
\end{abstract}

Outro proprietário direcionou sua preocupação, defendendo o controle do número de pousadas e leitos, pela possibilidade de faltar recursos naturais necessários para a atividade econômica do turismo no longo prazo.

Eu acho que deve ter controle do número de pousadas e de leitos também. Não pode ser uma coisa extravagante assim. Enquanto tiver esse sistema de esgoto de forma precária, tem que ser estabelecido assim, porque, senão, daqui a pouco, vamos ter que importar água: não vai ter água para a gente tomar. (INFORMAÇÃO VERBAL).

Este mesmo proprietário complementou que o número de pousadas poderia até aumentar, caso fossem resolvidos problemas como o tratamento precário do esgo to na Ilha do Mel, PR. Alguns empreendedores criticaram também o fato de que 
algumas pousadas superlotam seus cômodos em alguns feriados, potenciando uma série de impactos ambientais.

O utra crítica refere-se à disparidade de tamanho entre as pousadas. Esse problema reside na falta de resolução dos aspectos que dizem respeito ao aforamento dos terrenos da Ilha, como o conflito entre as normas do SPU (Serviço do Patrimônio da União) e do IAP relacionadas às exigências de área construída, além da fiscalização insuficiente pelo órgão ambiental responsável. Estes aspectos foram destacados por um dos proprietários:

[...] há disparidade muito grande: tem pousadas enormes que têm terrenos grandes. Mas elas não têm 0 terreno de controle do IAP e sim do SPU. Tem gente aí com áreas de $4000 \mathrm{~ms}^{2}$. Então eles podem construir muito mais coisas, enquanto que pelo IAP o limite de terreno é de $500 \mathrm{~ms}^{2}$; a disparidade existe aí. (INFO RMAÇÃO VERBAL).

Ao lado disso, foi sugerido que a solução dos problemas de impacto ambiental poderia vir por meio de certificação de qualidade nas pousadas; não haveria, assim, relação direta entre impacto ambiental e a quantidade de leitos nas pousadas, mas pela capacidade das pousadas de administrar bem seus aspectos da gestão ambiental, como um dos proprietários destacou:

Sou a favor do controle da qualidade e da certificação das pousadas. No sentido de impacto ambiental e atendimento. D everia ter uma classificação: uma estrela, duas estrelas... Porque têm pessoas que jogam esgoto no rio e ele está nivelado a você. Não temos incentivos para tratarmos os resíduos. (INFO RMAÇÃO VERBAL).

Entre os que acreditam que não precisaria haver controle nenhum para 0 número de pousadas $10 \%$, defendem 0 argumento de que, com o tempo, o número de pousadas e leitos iria equilibrar-se, a partir do número de 5.000 visitantes estabelecido pelo IAP, pois "somente as pousadas mais capazes de competir sobreviveriam".

\section{CONCLUSÕES}

Apesar de a Ilha do Mel, PR possuir a imagem de local ecologicamente preservado e de contar com ferramenta da gestão do controle de demanda de visitantes, este destino turístico é objeto de impactos comprometedores da sua sustentabilidade. Verifica-se, no entanto, que os impactos são causados predominantemente na alta temporada, de dezembro a março, período de maior visitação turística.

Sobre a Capacidade de Carga da Ilha do Mel, PR, verificou-se pelo documento e estudo que a estabeleceu (Plano de G estão da Ilha do Mel, PR, 1996), que foram levados em conta apenas quatro variáveis para a decisão de seu limite, apesar de fazer referência a outros aspectos mais amplos de análise. Além disso, na realidade, verifica-se que a Ilha, em alguns dias da alta temporada, está recebendo muito mais pessoas do que havia sido calculado como o ideal neste plano, ou mesmo no que foi estabelecido na Resolução 036/ 95. Somado a isso, não foi estabelecido um controle para a capacidade de hospedagem, sendo verificado que o número de leitos aumentou consideravelmente de 1996 até a atualidade, colocando ainda mais em xeque a validade deste controle. Em consequência, sensível a este desequilíbrio, a maioria dos proprietários de pousada apóia a vinculação da oferta de leitos com a demanda de turistas.

Segundo a maioria dos empreendedores entrevistados, 0 controle da capacidade de carga é importante e necessário para garantir a sustentabilidade do turismo na Ilha do Mel, PR. Foram verificadas, contudo, discordâncias quanto ao número exato de visitantes estabelecido pela Resolução 036/ 95; a maioria destes considera baixo o número de turistas que está indo à Ilha: os turistas seriam insuficientes para dar suporte econômico aos empreendimentos, portanto, eles são a favor de aumentar este número estabelecido.

Por outro lado, como foi verificado pelo gráfico 1, o número de turistas ao local vem se reduzindo consideravelmente, inferindo-se que seja este, muito provavelmente, um fator que também contribui para a baixa procura por pousadas e a decorrente insatisfação econômica de muitos empreendedores. Conclui-se daí que pode estar havendo controle natural da demanda de turistas da Ilha do Mel, PR, visto que o desconforto causado pelo turismo desordenado pode estar afugentando os próprios turistas.

A pesar de os proprietários defenderem o turismo sustentável, no entanto, poucos foram aqueles que defenderam 0 estabelecimento da capacidade de carga, visando ao equilíbrio de aspectos nos âmbitos social, econômico e ambiental, em consonância com os princípios deste tipo de turismo. A maioria deles defende postura mais econômico-desenvolvimentista, objetivando a manutenção financeira dos empreendimentos, sem mencionar aspectos mais amplos da sustentabilidade que beneficiem a Ilha como um todo.

Neste sentido, quando algum fator, que não só o econômico, era mencionado para justificar o controle da capacidade de carga, a questão ambiental também recebia considerável atenção, sendo defendida a gestão ambiental das pousadas como a opção principal para reduzir impactos ambientais. Infere-se daí e de outros fatores já mencionados que esta preocupação com 0 meio ambiente esteja diretamente relacionada com a questão econômica, pois os impactos ambientais causadosao local, como também já vêm sendo retratado por inúmeros autores (SILVEIRA, 1998; NETO, 1999; ESTEVES, 2004; KIM, 2004; dentre outros), são considerados um dos principais, se não 0 principal, inibidor dos turistas. Cientes disso, alguns proprietários entendem que deve ser até diminuído o número de visitantes da Ilha, dando a entender uma clara preocupação com a proteção ambiental como indispensável estratégia econômica.

\section{REFERÊNCIAS}

ATHAYDE, S. F.; TOMAZ, L. M. Áreas naturais protegidas e comunidades locais da Ilha do Mel - PR - Brasil. Néítica 9, 1995.

BROWN, K.; TURNER, R. K.; HAMEED, H.; BATEMAN, I. Environmental carrying capacity and tourism development in the Maldives and Nepal. Enironmental Conservation, v. 24, p. 316-325, 1997.

CANEST RELLI, E; COSTA, P. Tourist Carrying Capacity: A Fuzzy Approach. Amals of Tamism Reerch v. 18, p. 295-311, 1991.

COORDENAÇÃO DO IAP PARA A ILHA DO MEL. Entreista concedich a Matias Pdi Sperb. Ilha do Mel, PR, 19 dez. 2005. 
DIAS, R. TunismoSustentáve eMeioAmbiente São Paulo. Atlas, 2003. ECOPARANÁ. Número de visitantes da Illa do Md - 2000 a 2004. Pontal do Sul, PR, 2005.

ELIAS, T. L.; MARTINEZ, J.; ESTEVES, C. J. O. Tunism e condiçoes debalneabilidadena Tllha do Md (Litoral do Paraná). Disponível em: <http:/ / geografia.igeo.uerj.br/ xsbgfa/ cdrom/ eixo3/ 3.3/ 285/ 285.htm> Acesso em: 13 nov. 2005.

ESTEVES, C. J. O. TưismoeQualidadeda Água na Illha do Md (Litoral do Paraná). Curitiba, PR, 2004: Dissertação (Mestrado em G eografia) - Universidade Federal do Paraná.

GOD OY, A. S. A pesquisa qualitativa e sua utilização em administração de Empresas. RAE - Revista de Administração de Empresas. São Paulo, v. 35, no 4, p. 65-71 jul. / ago. 1995.

HETZER, N. D. Enviranment, Tourism Culture D isponível em: <http:/ / www.fieu.edu/ ecosphere.shtml> Acesso em: 25 abril 2005. IAP - Instituto Ambiental do Paraná. Plano de Gestão da Illha do Md - Reatónio preiminar. Curitiba, 1996.

ITCF - Instituto de Terras, Cartografia e Florestas. Cdeân€ deLejs lação e Doammtação sdłre a Ilha do Md - 1946-1985. Curitiba, 1986.

KIM, K. M. Avaliação da sustentabilidade do moddo de desenvdvimento vigente na Ilha do Md - PR. Pontal do Paraná, 2004. Monografia (G raduação Ciências do Mar) - Universidade Federal do Paraná.

KRAEMER, M. C. Malhas da Pdbreza: exploração do trabalho de pescadores artesanais na Baía de Paranaguá. São Paulo, 1978, Dissertação (Mestrado em Ciências Sociais - Antropologia) - Pontifícia Universidade Católica de São Paulo.

LIND BERG, K.; MCCOOL, S. F. A critique of environmental carrying capacity as a mean of managing the effects of tourism development. Enurronmental Conservation, v. 25, p. 291-2, 1998.

MIECZKOWSKI, Z. Environmental issues of tarismand recreation. Chapter 7 "The issues of carrying capacity". Boston: University Press of America, 1995.

NETO, R. F. As inter-relaçães da energia détrica comaspetos de conforto emodemidade empequenas commidades. Um estudo de caso na ilha do mel - PR. Curitiba, 1999. Tese (D outorado em Meio Ambiente e D esenvolvimento) - Universidade Federal do Paraná.

PARANÁ. Resolução $n^{\circ}$ 036/ 95 - Disciplina o fluxo de turistas a Ilha do Mel. Diánio Oficial do Estado do Paraná. Curitiba, 28 dez. 1995.

PIRES, P. S. “Capacidade de Carga” como Paradigma de G estão dos Impactos da Recreação e do Turismo em Áreas Naturais. São Paulo. CRP/ ECA/ USP. Em: Tunismo em Análise ed. Aleph, v. 16 n 1, 2005.

RO D RIG UES, A. B. TunismoeDesenvdvimentoLocal. São Paulo. Ed. Hucitec, 2000.

RUSHMANN, D. Tunismo e Plangamento Sustentáve: a Proteção do Meio Ambiente. Campinas, SP. Ed. Papirus, 2001.

SALEEM, N. The destination capacity index: a measure to determine the tourism carrying capacity. Em: SEATON A.V. Taurism the state of the art. Ed. John Wiley \& Sons. Chichester, 1994.

SEMA - Secretaria de Estado do Meio Ambiente e Recursos Hídricos. Plano de Gestão Integado da Ilha do Md. Curitiba, 1996.

SHELBY, B.; HEBERLEIN, T. CaryingCapadityin Rereation Settings State University Press, Corvallis, OR, 1986.

SILVEIRA, M. A. T. Ecoturismo na Iha do Mel. Em: LIMA, R. E.; NEG RELLE, R. R. B. (Orgs.). Meio Ambiente e Desenvdvimento no Litaral do Paraná Curitiba: UFPR, p. 223 - 230, 1998.
WAHAB, S.; PIG RAM, J. J. Tounsm Develqment and Gronth London: Routledge, 1997.

YIN, R. K. Estudo de Casa plangjamento e mátodos. Porto Alegre: Bookmann, 2005. 
